\title{
Psychological and pedagogical aspect of choosing life goals for people of early old age
}

\author{
Natalia Shulga ${ }^{1, *}$, Natalia Belyakova ${ }^{1}$, Ekaterina Dubrovinskaya $^{1}$ \\ ${ }^{1}$ Russian State Social University, Russia
}

\begin{abstract}
The article considers peculiarities of elderly people conscious perceptions of their own future, as well as it considers how they focus on attainable goals and on connections of these goals with professional determination of elderly people in time perspective. Article describes theoretical approaches which touch the problem of connection of life goal choosing and the existence of human life. Using the method of nonlinear relationships, a close relationship of psychological factors and their mutual influence are highlighted. Psychological factors: "Caring for one's own health" and "Mastering a profession and skill"; "Do good for other people" and "Master the profession and skill"; "Have good friends" and "Master the profession and skill"; "Master the profession and skill" and "Travel the world"; "Finding a calling and" Traveling the world "are presented as a way for older people to select goals. Ways of choosing goals by people of late adulthood are considered in a two-year time perspective. Attention is focused on the implementation of time control in connection with understanding the finiteness of life. Article clarifies the role of psychological and pedagogical aspect as possible and accessible way in search of answers to life challenges of elderly people is also discussed. Authors consider the role of psychological help and pedagogical impact on elderly people obtaining the opportunity to place independently real and attainable goals, being fully aware of their sense and the meaning of their own existence.
\end{abstract}

\section{Problem statement and relevance}

While becoming elderly people are used to deal more often than before with the existential questions. Elderly people age category is such a category of people who were once successful with a still good professional training and well established communicative skills, people with anticipation experience who are able to cope with difficult life situations, who have high level of resilience and who manage to find solutions in extreme life conditions. People who managed to adapt to numerous changes in social life in times of Dashing 90ties in Russia, now try to adapt to conditions of life in new times of Great optimization. One part of them found themselves in newly obtained professions, another realized themselves in social work, but most part of elderly people presented at labor market have jobs which very often do not respond to their intellectual potential and many of them are jobless. People with rich professional experience, who were high class professionals in their past now often have

\footnotetext{
* Corresponding author: bogomazovargsu@mail.ru
} 
to perform simple working functions which do not meet nor moral nor financial expectations of them due to radically changed economic situation and rapid social changes. For many of them questions of defining their life goals closely intertwine with questions of the meaning of life. The absence of answers to all these questions lead them to idea that their life has come to dead end. In this situation the awareness of a person of her/his age and finiteness of life are important factors. According to Schanina E.V. [1], am important factor for finding the way out of the situation is a cognition by individuals of their own age and finiteness of life in general. Meaning of life when considered along with awareness by elderly people of the limits of time perspective and finiteness of life, along with loosing their positions in a certain social group very often could have a risk to become lost for the subject of life in older age. And the loss of life perspectives could be considered the most painful for them.

How to obtain independently existential senses for the individual, who has realized the irreversibility of time and the pressure of age? How to construct life plans and set goals, and what meaning and sense of them could be? In accordance with autors: Korotaev A.V., Novikov K.E., Shulgin S.G. [2], Sasmita Kusumastuti, Marloes G. M. Derks, Siri Tellier, Ezio Di Nucci, Rudi G. J. [3], Nesterova A.A., Zhuchkova S.M. [4], Ana Cecilia Reyes Uribe [5], persons with high level of resilience and viability with active life position are able to construct definite strategies and reach the goals they have set. But social group of elderly people is not homogenous nor by health, nor by resilience indicators. For less active part of this social group of elderly people setting of goals when their senses are not always definite or they were lost somewhere on a road of life, at which they met more questions than found clear and understandable answers could become extremely difficult and hard to overcome psychological task. Complication of such psychological position could often lead to depressive position, addictions, alcoholism, use of surfactants of different kind. While having their life defending forces becoming weaker due to age factor and due to the combination of biological, social and psychological signs, the probability of psychosomatic diseases rises.

Relevance of once found patterns of impact of emotional reactions to autonomic nervous system with consequent organ-target failure in accordance with psychosomatic medical science nor in our time of rapid global social changes.

While considering the ability to goal setting of a person being in older age it's important to highlight that this ability is connected not only to meaning of life but to values settings as well, to motive of getting knowledge, to volitional effort and psychological readiness to labor activity and activity in general sense, according to Basimov M.M., Shulga N.I [6]. Elderly persons with a low level of resilience do not possess enough experience and skills to cope with difficult life situations independently. Those whose volitional effort is weak are not able to obtain new meaning for active life. Without definite psychological support and professional pedagogical maintenance finish line of life for such a subject of old age would not hide far beyond the horizon.

\section{The aim of the study}

Elderly people category according to the WHO is framed by 60 to 75 years. What characterizes this age period for people who are able to lead active labor life? For those of them who continue their professional activity different new requirements of social life are rising, especially because of innovations. For those who went away from their profession the framework of social activity becomes limited, and as a result their social circle narrows. Partially they loose their connection to former social group. Elderly people who are not engaged in social life, but whose health allows them to remain active, face the question of meaning of life and question of goal choice. It's important to consider the possibilities of pedagogical impact on elderly people and of granting them psychological help in their search of meaning of life and choosing attainable goals. In difficult life situations it could be 
impossible for them without necessary help to find independently lost meaning of life and it is even more complicated for them to set any new goals. Under these conditions the role of existing in our society possibilities of bringing them psychological help, pedagogical impact could not be overestimated. And only one general aim should be: not to allow persons to push themselves out of life in direct and portable sense, accjrding to Basimov M.M., Shulga N.I [6].

\section{Theoretical research problem: an analysis}

In modern foreign philosophical and psychological concepts of the problem developing in the framework of existential philosophy, social psychology and pedagogics we see the everlasting interest to works of such classic humanistic thinkers as Victor Frankl, Carl Rogers, Wilhelm Reich, Erich Fromm and many others. The research of human life existence by V. Frankl (The Will to Meaning; Psychotherapy and Existentialism; Man's Search for Meaning etc) has direct connection to study of life strategies to survival, to human confrontation to challenges of a World War. In these moments, the major value - life itself comes out to foreground. V. Frankl worked out psychological method of treating human by a word - the method of logotherapy, the method of paradoxical intention.

Erich Fromm studied human existence as a subject of social life in his work "Sane Society". He brightly represented how human beings in course of technical progress alienated from themselves, from their natural purpose, and argued that the impact of rising social demands actively promoted neurotization of a personality. The author tried to find answers to questions how to secure mental health of personality, and discussed psychological and pedagogical opportunities to confront destroying factors of personality's mental integrity. He saw the way out from this situation in a creativity, since homo creativus, creative human being seeks happiness in creative work, when she/he becomes the owner of the work results, of her/his own creature, and obtains happiness in creative work and find the answer to the question of meaning of life.

It's not occidental that in the same work of E. Fromm we find Albert Einstein's opinion about human existence ('Why Socialism?'). He wrote that the individual as a product of social life is conscious of her/his dependence upon society, but doesn't consider this dependence as a protective force. In contrary individuals feel the threat to their natural rights, or even to their economic existence and Einstein saw in that the crisis of our time.

Existentialist philosopher Karl Jaspers considered the concept of meaning as intertwined psychiatric phenomena of complex human mental life: "The plexus, in which being for us resides, allow the cognition from one side to move ahead limitlessly in all, what becomes for us the object, but it creates, from the other side, in comprehensive the impassable border, recognition of which at the same time inspires the meaning of our cognition".

Social psychologists, who are studying human life, its meaning, goal setting and choosing life strategies by elderly people, considered the problem of meaning in close relationship with goal choice by people of old age. They disclosed problems of psychological interaction of a psychologist with the representatives of pedagogics and social workers in course of practical aid to persons in need. They characterize life strategies and disclose their regular relationship of different motives with these or that choices and actions. Social psychologists V. Humboldt, I. P. Leal [7], Rifky Tkatch, Shirley Musich, Stephanie MacLeod, Sandra Kraemer, Douglas G. Armstrong [8], Brad J. Stenner, Jonathan D. Buckley, Amber D. Mosewich [9] touches existential problems of personalities, their value orientations and moral norms, analyzes main directions and modes of constructing life path of a healthy personality.

Thus, relying on socio-psychological and philosophical studies it could be seen how closely in general concepts of life goals and meaning of life are connected. The importance 
of psychological readiness and participation in educational process give elderly people the opportunity of self-realization, give them knowledge of how to construct life goals and in perspective to get them finally the feeling of self-satisfaction. Hence, the set of life goals will be inextricably connected with the understanding of a meaning of life.

Pedagogical aspect of learning consist of a skill of the person of older age to get necessary skills and methods, which will contribute to viability and resilience in overcoming of personality crisis in search of existential meaning, in gaining will effort and possibility to construct their own life.

If a health of a person is in good state, the age is not a factor which prevent elderly people to get second higher education and for the opportunity to be retrained for another profession. Many elderly people after their professional activity is over do not find themselves in life and are asking for a meaning of a new stage in their life. But they find it, when get ready for inclusion into educational process. Educational process contributes to continuing development of the level of knowledge, helps to develop personality's adaptability and ability to make strategic steps in reaching desirable objectives. Psychological follow-up strengthens the ability to cope with age difficulties, contributes to support the psychological and general level of health. Process of education helps a person to percept adequately and to adapt to traumatic factors of social origin, and that significantly lower the anxiety of elderly people. As suggested in the works Glozman Zh.M., Naumova V.A. [10], Tsvetkova N.A., Rybakova A.I., Startseva N.G. [11], elderly people are able to set life goals in time perspective which they can grasp and they are able to keep timing and goal attainment under their control. Their previous specific professional experience already has given them practical knowledge of overcoming difficulties in complicated life situations and to keep their control over circumstances. A control to some extent could be considered as psychological activity of any individual with adequate perception of difficult life situations.

Elderly people as participants of educational process are developing their personal level of the process of cognition. They get new opportunities for personal growth, they get answers to difficult questions which are set to them by life and answers to existential questions are among them. All together, that help them to set attainable goals and support active life style. As a result they feel their own necessity, their own belonging to group, to community, to people, they feel the need for them of somebody or something.

Russian scholars of younger Kislyakov, P.A., Shmeleva, E.A., Silaeva, O.A., Belyakova, N.V., Kartashev, V.P. [12] generation focus on formation of personality settings for success in a framework of pedagogical educational process. In Russian socio-psychological science dominate substantive side of a question, that means that not only personal qualities of a person matters - such as stress resistance -, but socially important characteristics as well the skill of setting goals, making choice of strategies of goals achievement consciously, being active and socially useful. This set of qualities could serve as a basis for psychological satisfaction and finally contributes to support of psychological integrity of elderly people, who brought the 'lion's share' of their health during their labor youthfulness.

\section{Methodology and methods, description of research of getting empirical data}

This empirical research was conducted with the use of survey and statistical processing of data got and gave definite results of mutual interference of parameters presented below. Respondents' survey was based on method from 'The Study of life strategies' by M.O. Mdivani and P.B. Kodess, used by Basimov M. M. and Shulga N. I. in the study [13]. This method helps to study the contents of goals setting of people in time perspective of test subjects in two, five, ten and fifteen years. Mdivani \& P.B. Kodess selected five meaningful factors describing life strategy. Structure assessment highlights the level of cognition of life 
strategy. In this study we have chosen two-year period of perspective presented. In this case we consider the scale 'The mode of goals choosing' (MGC) of cognitive component. The authors of the method substantiated its theoretical credibility using the basics of philosophical and psychological studies.

The number of studies devoted to constructing of personal life and to life goals and strategies continues to grow in recent years both in the West and Russia. But still there are few works, describing methods of the research of psychological phenomena of the kind.

Resulting statistics was got with the help of the method of mathematical statistics of nonlinear relationships of compared parameters values described by M.M. Basimov [13]. To study the interference of variables the compared parameters are evaluated " $X$ " for triads according to scales ' $\mathrm{Y}$ ". Resulting statistics data are presented in comparison with Pearson correlation coefficient.

1. Figures of dependence of parameter 'Self-care of health (MGS in two years) (X24)' with parameter 'To learn new trades and skills (MGS in two years) (X15)' presented as comparable values of parameter X25 for triads of scale X15 are presented in Table 1.

Table 1. Figures of dependence of parameter 'Self-care of health (MGS in two years) (X24)' with parameter 'To learn new trades and skills (MGS in two years) (X15)' presented as comparable values of parameter X25 for triads of scale X15.

\begin{tabular}{|c|c|}
\hline Triads of scale X15 & $\begin{array}{c}\text { Relative weight of parameter X24 } \\
\text { for triads }\end{array}$ \\
\hline X15-3 & 2296 \\
\hline X15-2 & -8578 \\
\hline X15-1 & 11437 \\
\hline
\end{tabular}

Forms of dependence and the degree of manifestation of parameters of scales are presented in figures:

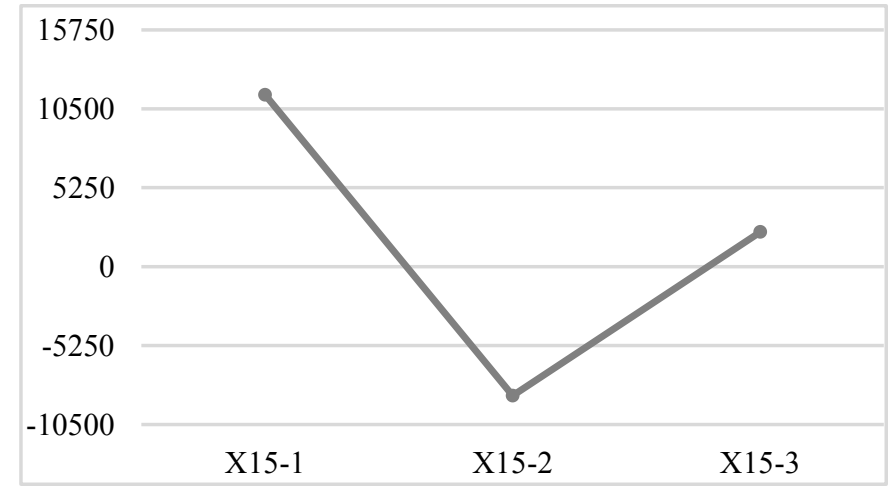

Fig. 1. Dependence of parameter 'Self-care of health (MGS in two years)' (X24) with parameter 'To learn new trades and skills (MGS in two years) (X15)'.

Dependence of parameter 'Self-care of health' with parameter 'To learn new trades and skills' presents the dependence with maximal value in first triad, which take turn by radical fall to minimal value in second triad of independent parameter (-8578). And then we see rise in third triad up to the value (2296), but the rise doesn't reach the level of first triad. Tie strength coefficient is $0.86(0.65)$, in comparison correlation coefficient is 0.05 .

Thus, self-care of health and learning new trades and skills are two interrelated goals and the process of their mutual interference is complex and heterogeneous. 
2. Figures of dependence of parameter 'Doing good for others (MGS in two years) (X25)' with parameter 'To learn new trades and skills (MGS in two years) (X15)' presented as comparable values of parameter X25 for triads of scale X15 are presented in Table 2.

Table 2. Figures of dependence of parameter 'Doing good for others (MGS in two years) (X25)' with parameter 'To learn new trades and skills (MGS in two years) (X15)' presented as comparable values of parameter X25 for triads of scale X15.

\begin{tabular}{|c|c|}
\hline $\begin{array}{c}\text { Triads of scale } \\
\text { X15 }\end{array}$ & $\begin{array}{c}\text { Relative weight of parameter X25 } \\
\text { for triads }\end{array}$ \\
\hline X15-3 & 5003 \\
\hline X15-2 & -9058 \\
\hline$X 15-1$ & -199 \\
\hline 8750 & \\
4375 & \\
0 & \\
-4375 & \\
-8750 & \\
-13125 & $X 15-2$ \\
\hline
\end{tabular}

Fig. 2. Dependence of parameter 'Doing good for others (MGS in two years) (X25)' with parameter 'To learn new trades and skills (MGS in two years) (X15)'.

Dependence of parameter 'Doing good for others' with parameter 'To learn new trades and skills' presents the dependence with a negative value, which is very close to zero in first triad (-199) with a radical fall to minimal values in a second triad (-9058). Then we see steep rise to maximal values in third triad (5003). Tie strength coefficient is $0.64(0.60)$, correlation coefficient is 0.20

Thus, the goal of learning new trades and skills is connected with a goal of doing good for others in an ambiguous way and is very complicated.

3. Dependence of parameter 'Having good friends (MGS in two years) (X29)' with parameter 'To learn new trades and skills (MGS in two years) (X15)' presented as comparable values of parameter X29 for triads of scale X15 are presented in Table 3.

Table 3. Dependence of parameter 'Having good friends (MGS in two years) (X29)' with parameter 'To learn new trades and skills (MGS in two years) (X15)' presented as comparable values of parameter X29 for triads of scale X15.

\begin{tabular}{|c|c|}
\hline $\begin{array}{c}\text { Triads of scale } \\
\text { X15 }\end{array}$ & $\begin{array}{c}\text { Relative weight of parameter X29 } \\
\text { for triads }\end{array}$ \\
\hline
\end{tabular}




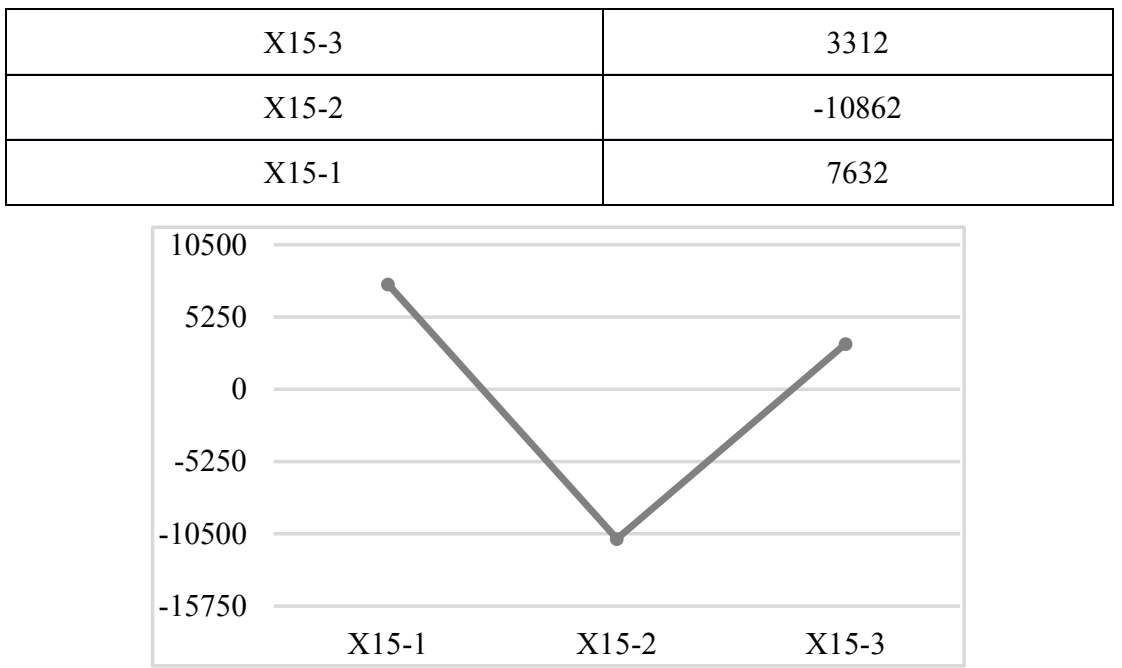

Fig. 3. Dependence of parameter 'Having good friends (MGS in two years) (X29)' with parameter 'To learn new trades and skills (MGS in two years) (X15)'.

Dependence of parameter 'Having good friends' with parameter 'To learn new trades and skills' presents the dependence with maximal value in first triad (7632). It takes turn by radical fall to minimal value in second triad (-10862) and by rise to positive values in third triad up (3312). In the third triad it doesn't reach maximal values of the first triad. Tie strength coefficient is $0.91(0.37)$, correlation coefficient is 0.10 .

Hence, goals of having good friends and learning new trades and skills are closely connected, but this relationship is complicated and heterogeneous.

4. Dependence of parameter 'To learn new trades and skills (MGS in two years) (X15)' with parameter 'Traveling round the globe (MGS in two years) (X16)' presented as comparable values of parameter X15 for triads of scale X16 are presented in Table 4.

Table 4. Dependence of parameter 'To learn new trades and skills (MGS in two years) (X15)' with parameter 'Traveling round the globe (MGS in two years) (X16)' presented as comparable values of parameter X15 for triads of scale X16.

\begin{tabular}{|c|c|}
\hline $\begin{array}{c}\text { Triads of scale } \\
\text { X16 }\end{array}$ & $\begin{array}{c}\text { Relative weight of parameter X15 } \\
\text { for triads }\end{array}$ \\
\hline X16-3 & 12587 \\
\hline X16-2 & -4504 \\
\hline X16-1 & -1440 \\
\hline
\end{tabular}




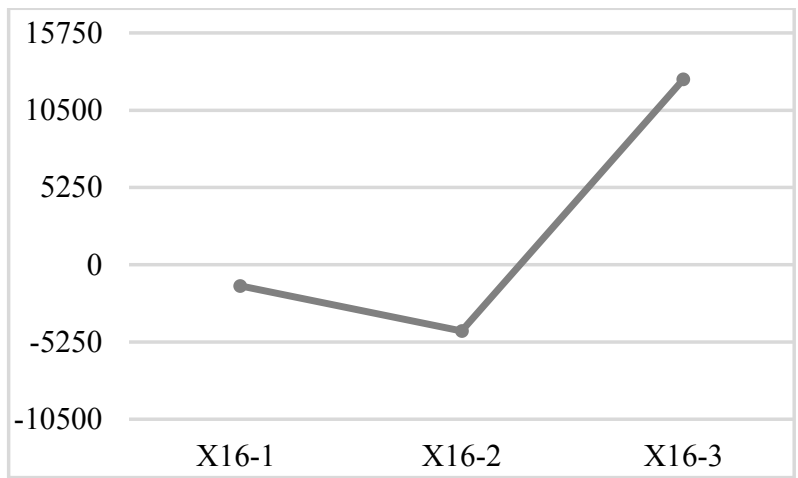

Fig. 4. Dependence of parameter 'To learn new trades and skills (MGS in two years) (X15)' with parameter 'Traveling round the globe (MGS in two years) (X16)'.

Dependence of parameter 'To learn new trades and skills' with parameter 'Traveling round the globe' presents a dependence with low negative value in the first triad (-1440), which takes turn to fall to minimal negative values in the second triad (04504). Then we see steep rise to maximal values in the third triad (12587). Tie strength coefficient is $0.56(0.45)$, correlation coefficient is 0.27 .

Hence, in that case we see interference of two parameters, but as in previous three cases this interference is heterogeneous and complex, so that creates opportunity to new research.

5. Dependence of parameter 'To find calling in life (MGS in two years) (X17)' with parameter 'Traveling round the globe (MGS in two years) (X16)' presented as comparable values of parameter X17 for triads of scale X16 are presented in Table 5.

Table 5. Dependence of parameter 'To find calling in life (MGS in two years) (X17)' with parameter 'Traveling round the globe (MGS in two years) (X16)' presented as comparable values of parameter $\mathrm{X} 17$ for triads of scale X16.

\begin{tabular}{|c|c|}
\hline Triads of scale X16 & $\begin{array}{c}\text { Relative weight of parameter X17 for } \\
\text { triads }\end{array}$ \\
\hline $\mathrm{X} 16-3$ & 9833 \\
\hline $\mathrm{X} 16-2$ & -4790 \\
\hline $\mathrm{X} 16-1$ & -821 \\
\hline
\end{tabular}

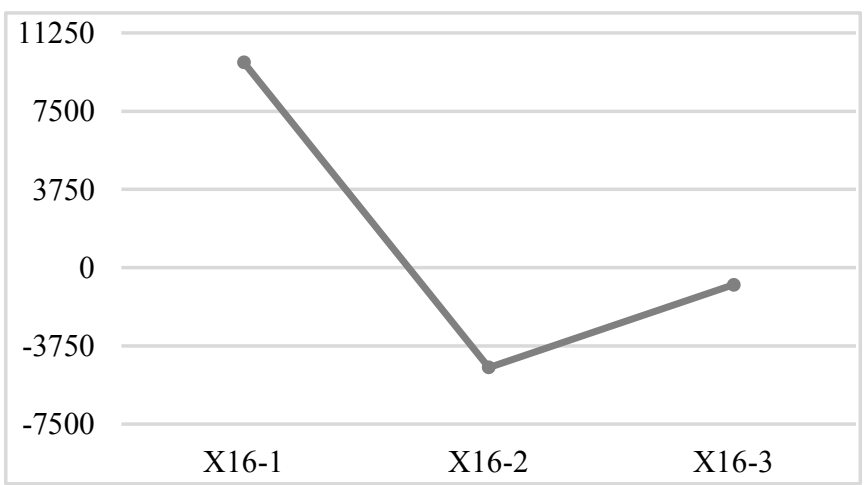

Fig. 5. Dependence of parameter 'To find calling in life (MGS in two years) (X17)' with parameter 'Traveling round the globe (MGS in two years) (X16)'. 
Dependence of parameter 'To find calling in life' with parameter 'Traveling round the globe' presents the dependence with maximal high positive value in the first triad, which makes turn with a steep fall to minimal negative values in the second triad (04790). Then we see insufficient rise of negative values bound to zero in the third triad $(-821)$. Tie strength coefficient is $0.52(0.14)$, correlation coefficient is 0.24 .

Hence, in the presented case we see complexity and homogeneity in dependence's parameters as in all previous cases.

\section{Conclusion}

Thus, it could be said, that self-care of health, being good for other people, the opportunity of having good friends if we consider them as methods of choosing valuable goals are in complex and homogeneous dependence with the goal of learning new trades and skills for elderly people (MGS in two years).

The goals of learning new trades and skills and a goal to find calling in life are closely connected with a willing of traveling around the world and that means enduring interest to get knowledge about the world around.

In case of negative minimal values or values close to zero we see the elements of stagnation in goal setting process and in the process of choosing life strategies. The process of stagnation is worth to link with the absence of answers to many life questions, which are closely connected with questions of existence of human life. That witnesses once again the necessity to include outer psychological and pedagogical help for elderly people. That help is being brought to them in order to obtain the meaning of life and to get the ability to set goals and choose action strategies in construction of their own life path independently.

While summarizing calculations performed it is possible to ascertain the fact that the process of choosing goals of tested individuals is complex and heterogeneous and that it depends on learning new trades and skills by them. Choosing a goal and search of meaning of life are not always possible without inclusion of a personality into educational environment. That environment, which has theoretical and methodological basis, as well as experienced pedagogical potential of high class professionals, is able to supply elderly people with the necessary theoretical knowledge, practical experience, skills in obtaining the lost meaning. That environment could help elderly people to set goals and give them motives to pursue knowledge about surrounding life.

Competitiveness of individual at contemporary labor market is due to many factors of personal potential: adaptive individual psychological features, high communicative skills, the knowledge of how to construct interpersonal relations and high professionalism. Hence, it is necessary for elderly people to match present requirements.

Trying to match these requirements many universities grant the opportunities of professional training distantly. Distant educational resources make accessible educational process for people of different age optimizing for them use of time and material resources etc. The guidance of experienced teachers is a great opportunity for elderly people to develop not only their professional level but to develop high cognitive level as well, which helps to construct the logic of scientific research independently. As discussed Kosharnaya G.B., Schanina E.V. [14], Pryazhnikov N.S. [15], Anikina E.A. Ivankina L.I. [16], elderly people included into educational process in contemporary world are the phenomenon which is supported by governmental and private structures, and they are promoted by public opinion. Positive result of pedagogical process helps to lower anxiety of elderly and to some extent prevents them from neurotic disorders, helps to feel themselves more confidently. All these results help to support psychological integrity of personality and supports general level of health. This benefits the participants of education process as well as society as a whole.

Many governmental and private structures now have organized centers of psychological 
help. Social services of provincial and regional centers have offices of psychological help, granting their clients the opportunity to solve their individual problems as well as problems of interpersonal communication. Centers of psychological help provide different kinds of services to solve elderly people problems.

\section{Reference}

1. E.V. Schanina, J. Izvestia Vysshikh Uchebnykh Zavedenii 2(42), 138-148 (2017) DOI: $10.21685 / 2072-3016-2017-2-$

2. A.V. Korotaev, K.E. Novikov, S.G. Shulgin, Journal of Sociology of Power 1(31), 114142 (2019) DOI: 10.22394/2074-0492-2019-1-114-142

3. S. Kusumastuti, M.G.M. Derks, S. Tellier, E. Di Nucci, R.G.J. Westendorp, Maturitas 93, 4-12 (2016) http://dx.doi.org/10.1016/j.maturitas.2016.04.010

4. A.A. Nesterova, S.M. Zhuchkova, Bulletin of Moscow State Regional University. Series: Psychological Sciences 1, 60-72 (2018) DOI: 10.18384/2310-7235-2018-1-6072

5. A. Cecilia Reyes Uribe, Journal of Behavior, Health \& Social Issues 7(2), 9-17 (2016) DOI:10.5460/jbhsi.v7.2.52888

6. M.M. Basimov, N.I. Shulga, Scientific notes of the Russian State Social University 18, 15-24 (2019) DOI: 10.17922/2071-5323-2019-18-1-15-24

7. S.V. Humboldt, I.P. Leal, European Psychiatry 27, 1 (2012) https://doi.org/10.1016/S0924-9338(12)75189-1

8. R. Tkatch, S. Musich, S. MacLeod, S. Kraemer, D.G. Armstrong, Geriatric Nursing 38(6), 485-490 (2017) http://dx.doi.org/10.1016/j.gerinurse.2017.02.009

9. B.J. Stenner, J.D. Buckley, A.D. Mosewich, Journal of Sport and Health Science (2019) https://doi.org/10.1016/j.jshs.2019.11.003

10. Zh.M. Glozman, V.A. Naumova, Russian psychological journal 3(15), 25-51 (2018) DOI: $10.21702 /$ rpj.2018.3.2

11. N.A. Tsvetkova, A.I. Rybakova, N.G. Startseva, Bulletin of Moscow State Regional University. Series: Psychological Sciences 4, 27-37 (2015) DOI: 10.18384/2310-72352015-4-27-37

12. P.A. Kislyakov, E.A. Shmeleva, O.A. Silaeva, N.V. Belyakova, V.P. Kartashev, SHS Web of Conferences 28, 01056 (2016) DOI: 10.1051/shsconf/20162801056

13. M.M. Basimov, N.I. Shulga, Scientific notes of the Russian State Social University 18, 15-24 (2019) DOI: 10.17922/2071-5323-2019-18-1-15-24

14. G.B. Kosharnaya, E.V. Schanina, Bulletin of the Peoples' Friendship University of Russia. Series: Sociology 3(19), 481-493 (2019) DOI: 10.22363/2313-2272-2019-19-3481-493

15. N.S. Pryazhnikov, Vestnik of Moscow University, Series 14: Psychology 4, 85-101 (2017) DOI: 10.11621/vsp.2017.04.85

16. E.A. Anikina, L.I. Ivankina, Journal of Well-being Vectors: Economics and Society 2(33), 63-71 (2019) DOI: 10.18799/24056537/2019/2(33)/964 